\title{
Adaptive Artificial Intelligence Based Model Base Controller: Applied to Surgical Endoscopy Telemanipulator
}

\author{
Farzin Piltan \\ Industrial Electrical and Electronic Engineering SanatkadeheSabze Pasargad. CO (S.S.P. Co), NO:16, PO.Code 71347- \\ 66773, Fourth floor, Dena Apr, Seven Tir Ave, Shiraz, Iran \\ E-mail:SSP.ROBOTIC@gmail.com
}

\begin{abstract}
Ali Badri
Industrial Electrical and Electronic Engineering SanatkadeheSabze Pasargad. CO (S.S.P. Co), NO:16, PO.Code 7134766773, Fourth floor, Dena Apr , Seven Tir Ave, Shiraz, Iran E-mail:SSP.ROBOTIC@yahoo.com

Javad Meigolinedjad

Industrial Electrical and Electronic Engineering SanatkadeheSabze Pasargad. CO (S.S.P. Co), NO:16, PO.Code 7134766773, Fourth floor, Dena Apr , Seven Tir Ave, Shiraz , Iran

E-mail:SSP.ROBOTIC@yahoo.com

\author{
Mohammad Keshavarz \\ Industrial Electrical and Electronic Engineering SanatkadeheSabze Pasargad. CO (S.S.P. Co), NO:16, PO.Code 71347- \\ 66773, Fourth floor, Dena Apr, Seven Tir Ave, Shiraz, Iran \\ E-mail:SSP.ROBOTIC@yahoo.com
}

\begin{abstract}
This research involved developing a surgical robot assistant using an articulated PUMA robot running on a linear or nonlinear axis. The research concentrated on studying the artificial intelligence based switching computed torque controller to localization of an endoscopic tool. Results show that the switching artificial nonlinear control algorithm is capable to design a stable controller. For this system, error was used as the performance metric. Positioning of the endoscopic manipulator relative to the world coordinate frame was possible to within 0.05 inch. Error in maintaining a constant point in space is evident during repositioning however this was caused by limitations in the robot arm.
\end{abstract}

Index Terms - Surgical Robot Assistant, Computed Torque Like Methodology, Fuzzy Logic Controller, Sliding Mode Switching Part, Telemanipulator

\section{Introduction}

Robots are typically thought to be used for industrial purposes however they are beginning to gain the attention of the medical field. Telemanipulator is collection of links that connect by joints, these joints can be revolute and prismatic that revolute joint has rotary motion around an axis and prismatic joint has linear motion around an axis. Each joint provides one or more degrees of freedom (DOF).

Surgery is a medical procedure involving an incision in the human body performed to repair damage or arrest disease [1]. In a fully invasive operation, an open incision is made that is large enough for the surgeon to view the internal organs and perform the operation. For example, in open-heart surgery a long incision is made along the sternum, after which the sternum is split and retracted (median sternotomy) [2]. These open incisions increase trauma to a patient beyond what is experienced from the actual repair. After the operation, the patient must heal from trauma associated with the repaired organs and from the open incision. This results in long recovery times and opportunities for infection [3]. Endoscopic Surgery, also called Minimally Invasive Surgery (MIS), is a type of operation that has been developed to reduce trauma associated with making these large open incisions. This type of operation involves viewing the operational field on a television monitor by inserting a special camera, called an endoscope, through a small incision in the skin. To perform the operation, "long, thin, manually operated instruments" are inserted through other small incisions called trocars [3]. This type of surgery reduces the size of the open incisions and therefore results in less pain 
and scarring after surgery, faster recovery times, and less risk of infection [4].

Endoscopic surgery does have benefits over fully invasive surgery but there are also several disadvantages associated with performing this type of operation. The two basic disadvantages involve viewing the internal operational field and the surgical tool interface. Using an endoscopic camera, the operational field is viewed on a 2-D television monitor providing only a limited view with no depth perception. Advances in visual technology have provided surgeons with equipment that allow them to view the field in 3-D however this technology is expensive [5]. Another disadvantage is that the endoscope is operated by a surgical assistant. This requires the surgeon to communicate motion instructions which becomes difficult when giving instructions such as how far to move the endoscope and in which direction. It has also been reported that small tremors from the scope-holding assistant, magnified onto the television monitor, can cause nausea among the surgical team [5]. Disadvantages associated with the surgical tool interface involve the endoscopic tools and the way that the operation is performed. Often the endoscopic tools are heavy, lacking ergonomic design, and do not have the same DOF/dexterity as a human hand [6-7]. As mentioned before, these tools are inserted through small incisions in the patient to perform the operation. This creates the fulcrum/lever effect whereas the surgeon is required to transpose each hand motion to get the desired internal motion [8]. For example, if it is desired to move the tool manipulator to the left within the patient the surgeon must transpose this motion in his mind and move the tool handle to the right. Surgeons must also deal with the amplification of tremors in their hands due to the fulcrum/lever effect and the length of the tools [3]. Performing an operation through small incisions using endoscopic tools removes the ability for a surgeon to use the sense of touch to gain more information about the internal tissue (haptic feedback). Tools that provide surgeons with this type of information are being developed, however they are not yet in use [9]. In the late 1980's, researchers motivated by the limitations of endoscopic surgery turned to robotic technology to make improvements [10]. Although the idea of using robotics for telepresence surgery was not a new idea at this time, research and development into this concept rapidly progressed around the success of MIS techniques and became possible with advancements in computing power [10]. By 1998, two major companies had developed surgical systems approved by the FDA for commercial use. Computer Motion in Goletta, California developed the Zeus Surgical System and Intuitive Surgical in Sunnyvale, California developed the daVinci Surgical System. Currently only the daVinci is in production due to the merger of Computer Motion and Intuitive Surgical in 2003. Figure 1 shows DAVINCI Surgical robot System.

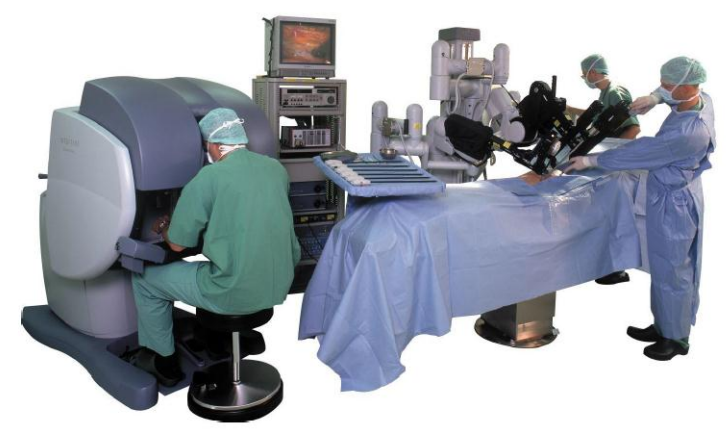

Fig. 1: Intuitive Surgical DAVINCI Surgical System

Controller (control system) is a device which can sense information from linear or nonlinear system (e.g., robot arm) to improve the systems performance and the immune system behavior [11-20]. In feedback control system considering that there are many disturbances and also variable dynamic parameters something that is really necessary is keeping plant variables close to the desired value. Feedback control system development is the most important thing in many different fields of safety engineering. The main targets in designing control systems are safety stability, good disturbance rejection to reach the best safety, and small tracking error[21-33]. At present, in some applications robot arms are used in unknown and unstructured environment, therefore strong mathematical tools used in new control methodologies to design nonlinear robust controller with an acceptable safety performance (e.g., minimum error, good trajectory, disturbance rejection). One of the most important nonlinear safety controllers is computed torque methodology which is used in nonlinear certain systems. One of the nonlinear stable controllers is computed torque controller, although this controller has been analyzed about industrial safety by many researchers but the first proposed was in the 1962 [34-55].This methodology is used in wide range areas such as in safety control access process, in aerospace applications and in IC engines because this methodology can solve some main challenging topics in safety control access such as resistivity to the external disturbance and stability. Even though, this methodology is used in wide range areas but, pure computed torque method has an important drawbacks beside uncertain system and also in presence of external disturbance. Uncertainty in system can causes some problems about safety in industrial factory. To solve this problem, neural network, fuzzy logic, and neurofuzzy are synergically combined with nonlinear classical controller and used in nonlinear, time variant, and uncertainty plant (e.g., robot). Fuzzy logic methodology (FLM) is one of the most important applications of fuzzy logic theory [30-41]. This method can be used to resolve the challenge in nonlinear, uncertain, and noisy systems. This method is free of some model-based techniques as in classical controllers. Control robot arms using classical controllers are based on robot arm dynamic modelling. These controllers often have many problems for modelling. Conventional 
controllers require accurate information of dynamic model of robot arms. When the system model is unknown or when it is known but complicated, it is difficult or impossible to use classical mathematics to process this model[32]. The main reasons to use fuzzy logic technology are able to give approximate recommended solution for unclear and complicated systems to easy understanding and flexible. Fuzzy logic provides a method which is able to model a controller for nonlinear plant with a set of IF-THEN rules, or it can identify the control actions and describe them by using fuzzy rules [32]. In various dynamic parameters systems to have safety training, training on-line adaptive control methodology is used. Fuzzy partly sliding switching adaptive method is used in systems which want to training parameters by expert knowledge. This method guarantees self tuning stability in safety in nonlinear and uncertain robot. Piltan et al., [40] have addressed comparative study between some adaptive fuzzy, and a new hybrid fuzzy control algorithm for robot arm control. They found that self-organizing fuzzy logic controller and proposed hybrid integrator fuzzy give the best performance as well as simple structure. Sltani and piltan [46] has proposed fuzzy adaption techniques for VSC to achieve robust tracking of nonlinear systems and solves the chattering problem. Conversely system's performance is better than variable structure controller; it is depended on nonlinear dynamic equation. This MIMO algorithm, applies to estimate the nonlinear dynamic parameters. Compared with the previous algorithm the numbers of fuzzy rules have reduced by introducing the variable structure surface as inputs of fuzzy systems.

The main goal of this research is to use a PUMA robot arm to perform the task of positioning an endoscopic tool. The research concentrated on the localization of the tool. An additional goal was to design a nonlinear stable and robust controller that would control the robot arm and provide functionality to an Intuitive Surgical EndoWrist. To control the surgical robotic system a switching based sliding computed torque control was created.

This paper is organized as follows; second part focuses on the medical robots, modeling dynamic formulation based on Lagrange methodology, introducing to feedback linearization controller (computed torque controller), fuzzy logic methodology and sliding mode controller to have a robust control. Third part is focused on the methodology which can be used to reduce the error, increase the performance quality and increase the robustness and stability. Simulation result and discussion is illustrated in forth part which based on trajectory following and disturbance rejection. The last part focuses on the conclusion and compare between this method and the other one's.

\section{Theory}

\subsection{Medical Robots}

Medical robots are tools that are being used by doctors to increase there capabilities and abilities to diagnose and cure diseases. They are not replacing doctors, but they are providing them with ways to perform better. Medical robots use range from autonomously performing a specific task during an operation to providing a human-machine interface that helps perform the entire procedure. There are several commercial companies that offer these systems however they are not being widely used. Some of the reasons for this revolve around questions regarding there effectiveness, safety, and cost [4]. Before talking more specifically about the different types and tasks of medical robots, it will help to give a definition of a robotic system. A robot is a mechanical system that is capable of performing a physical task [2]. It can be broken down into three main components: a control device, actuators and mechanical parts, and sensors. These three components allow a robot to interact with its environment. The controller is the brains of the system processing information and changing the actuators and mechanical parts based on this information. The actuators and mechanical parts provide the actual motion of the robot system. The sensors of the system allow the robot to get feedback on its position and in smarter systems data from the environment. Benefits of using robotics are that they can perform motions with very high precision repetitively without fatigue. They are capable of performing tasks that are not possible by humans such as lifting heavy objects and can hold a very precise position endlessly. From these benefits it is not hard to see why research is being done to implement robotics into some of the very difficult, fatiguing, and precise procedures that doctors/surgeons are performing. Medical robots can be divided according to their level of autonomy into three categories: active, semiactive, and passive [6-7]. Active medical robots autonomously perform a specific task during an operation that was programmed prior to the procedure. These robots take on an active role of performing a task under the supervision of the operator. Using this type of robot typically involves three steps: preoperative planning, program verification, and performing the operation. Semiactive medical robot takes on some of the features of both the passive and active medical robots. Similar to a passive robot, a surgeon will directly control the robotic system however the system will provide some type of constraint. This type of medical robot has been classified as having constrained cooperative control autonomy [9]. Passive medical robots are systems that perform motions only under the command of a human operator through some interface (joystick, foot pedal, etc.). These robots are also called surgical assistants, surgical extenders, and telemanipulators [9]. These robots are programmed to listen to external interfaces for motion commands and other tasks. As opposed to 
active medical robots, there is no preoperative motion commands programmed into the controller. Most of these robots are used for endoscopic procedures were they may perform the task of positioning an endoscope camera or actually manipulate the endoscopic tools under a surgeon's control. The robotic surgical system described in this research is a tool that would assist a surgeon in performing an endoscopic procedure. It does this by holding and physically manipulating an endoscopic tool under the direct control of the surgeon. It should be noted that the robot does not perform the surgery, but only provides assistance by manipulating the tools position and manipulator at the surgeons command. The system is classified as a passive medical robot, more specifically as a master-slave telemanipulator. In this type of system, the master has direct control over all movements of the robotic system. This is an essential feature for a surgical robot because only the surgeon should have the ability to move the robot arm. In between the surgeon and the Robotic System is a human machine interface that provides the surgeon with control of the system.

\subsection{Dynamic of Telemanipulator:}

The equation of a telemanipulator governed by the following equation $[1,4,15-29,41-53]$ :

$$
M(q) \ddot{q}+N(q, \dot{q})=\tau
$$

Where $\tau$ is actuation torque, $M(q)$ is a symmetric and positive define inertia matrix, $N(q, \dot{q})$ is the vector of nonlinearity term. This telemanipulator dynamic equation can also be written in a following form [1-29]:

$$
\tau=M(q) \ddot{q}+B(q)[\dot{q} \dot{q}]+C(q)[\dot{q}]^{2}+G(q)
$$

Where $\mathrm{B}(\mathrm{q})$ is the matrix of coriolios torques, $\mathrm{C}(\mathrm{q})$ is the matrix of centrifugal torques, and $\mathrm{G}(\mathrm{q})$ is the vector of gravity force. The dynamic terms in equation (2) are only manipulator position. This is a decoupled system with simple second order linear differential dynamics. In other words, the component $\ddot{q}$ influences, with a double integrator relationship, only the joint variable $q_{i}$, independently of the motion of the other joints. Therefore, the angular acceleration is found as to be [3, 41-53]:

$$
\ddot{q}=M^{-1}(q) .\{\tau-N(q, \dot{q})\}
$$

This technique is very attractive from a control point of view.

\subsection{Computed Torque Methodology:}

Computed torque controller (CTC) is a powerful nonlinear controller which it widely used in control of telemanipulator. It is based on feedback linearization and computes the required arm torques using the nonlinear feedback control law. This controller works very well when all dynamic and physical parameters are known but when the telemanipulator has variation in dynamic parameters, in this situation the controller has no acceptable trajectory performance[14]. In practice, most of physical systems (e.g., telemanipulators) parameters are unknown or time variant, therefore, computed torque like controller used to compensate dynamic equation of telemanipulator [13-23]. Research on computed torque controller is significantly growing on telemanipulator application which has been reported in [12-13, 21-55]. Vivas and Mosquera [12]have proposed a predictive functional controller and compare to computed torque controller for tracking response in uncertain environment. However both controllers have been used in feedback linearization, but predictive strategy gives better result as a performance. A computed torque control with non parametric regression models have been presented for a robot arm[13]. This controller also has been problem in uncertain dynamic models. Based on [13-22] and [12-13] computed torque controller is a significant nonlinear controller to certain systems which it is based on feedback linearization and computes the required arm torques using the nonlinear feedback control law. When all dynamic and physical parameters are known, computed torque controller works fantastically; practically a large amount of systems have uncertainties, therefore computed torque like controller is the best case to solve this challenge.

The central idea of Computed torque controller (CTC) is feedback linearization so, originally this algorithm is called feedback linearization controller. It has assumed that the desired motion trajectory for the manipulator $\boldsymbol{q}_{\boldsymbol{d}}(\boldsymbol{t})$, as determined, by a path planner. Defines the tracking error as:

$$
e(t)=q_{d}(t)-q_{a}(t)
$$

Where e (t) is error of the plant, $\boldsymbol{q}_{\boldsymbol{d}}(\boldsymbol{t})$ is desired input variable, that in our system is desired displacement, $\boldsymbol{q}_{\boldsymbol{a}}(\boldsymbol{t})$ is actual displacement. If an alternative linear state-space equation in the form $\dot{\boldsymbol{x}}=\boldsymbol{A} \boldsymbol{x}+\boldsymbol{B} \boldsymbol{U}$ can be defined as

$$
\dot{x}=\left[\begin{array}{ll}
\mathbf{0} & I \\
\mathbf{0} & \mathbf{0}
\end{array}\right] x+\left[\begin{array}{l}
\mathbf{0} \\
I
\end{array}\right] U
$$

With $\boldsymbol{U}=-\boldsymbol{M}^{-\mathbf{1}}(\boldsymbol{q}) \cdot \boldsymbol{N}(\boldsymbol{q}, \dot{\boldsymbol{q}})+\boldsymbol{M}^{-\mathbf{1}}(\boldsymbol{q}) \cdot \boldsymbol{\tau}$ and this is known as the Brunousky canonical form. By equation (4) and (5) the Brunousky canonical form can be written in terms of the state $\boldsymbol{x}=\left[\boldsymbol{e}^{\boldsymbol{T}} \dot{\boldsymbol{e}}^{\boldsymbol{T}}\right]^{\boldsymbol{T}}$ as [24]:

$$
\frac{d}{d t}\left[\begin{array}{l}
e \\
\dot{e}
\end{array}\right]=\left[\begin{array}{ll}
0 & I \\
0 & 0
\end{array}\right] \cdot\left[\begin{array}{l}
e \\
\dot{e}
\end{array}\right]+\left[\begin{array}{l}
0 \\
I
\end{array}\right] U
$$

With

$$
U=\ddot{q}_{d}+M^{-1}(q) \cdot\{N(q \cdot \dot{q})-\tau\}
$$


Then compute the required arm torques using inverse of equation (7), is;

$$
\tau=M(q)\left(\ddot{q_{d}}-U\right)+N(\dot{q}, q)
$$

This is a nonlinear feedback control law that guarantees tracking of desired trajectory. Selecting proportional-plus-derivative (PD) feedback for $\mathrm{U}(\mathrm{t})$ results in the PD-computed torque controller [24];

$$
\tau=M(q)\left(\ddot{q}_{d}+K_{v} \dot{e}+K_{p} e\right)+N(q, \dot{q})
$$

and the resulting linear error dynamics are

$$
\left(\ddot{q}_{d}+K_{v} \dot{e}+K_{p} e\right)=0
$$

According to the linear system theory, convergence of the tracking error to zero is guaranteed [24]. Where $\boldsymbol{K}_{\boldsymbol{p}}$ and $\boldsymbol{K}_{\boldsymbol{v}}$ are the controller gains. The result schemes is shown in Figure 2, in which two feedback loops, namely, inner loop and outer loop, which an inner loop is a compensate loop and an outer loop is a tracking error loop.

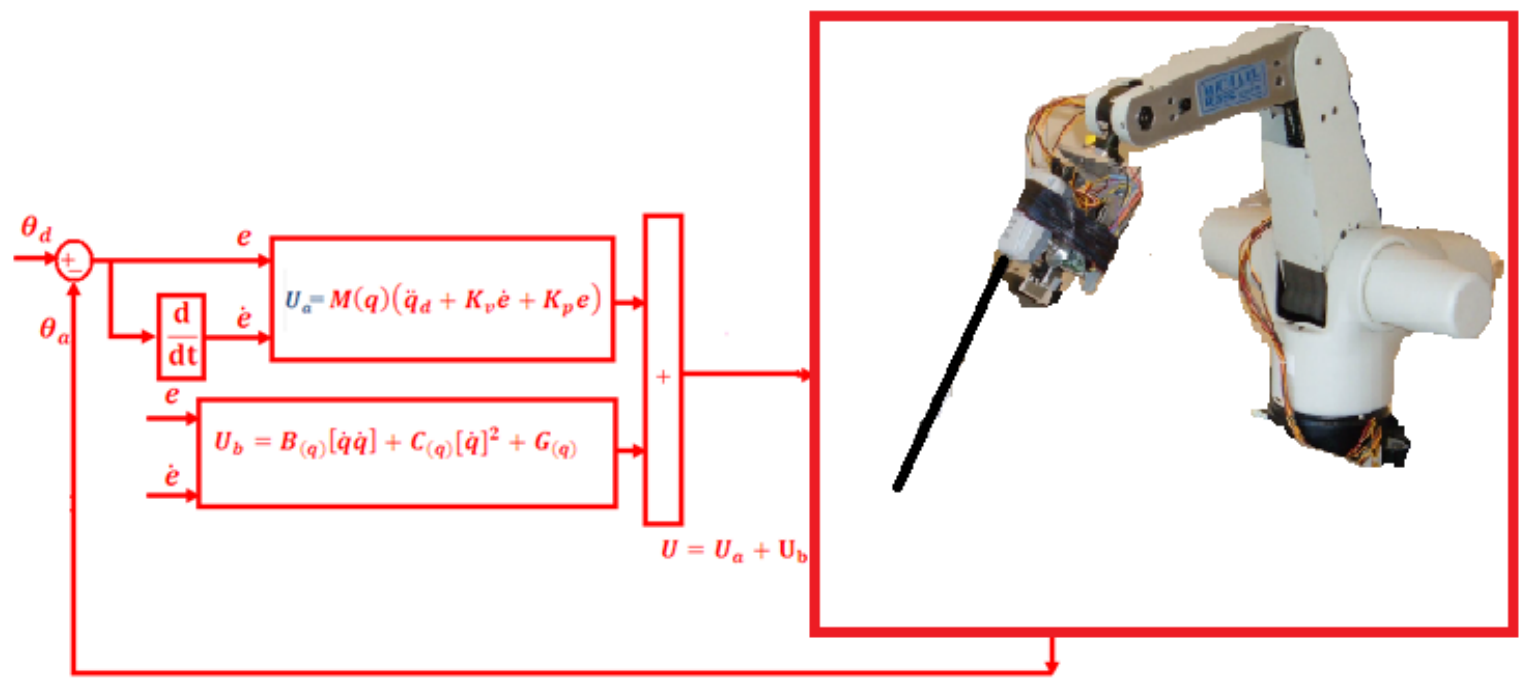

Fig. 2: $\quad$ Block diagram of PD-computed torque controller (PD-CTC)

The application of proportional-plus-derivative (PD) computed torque controller to control of PUMA telemanipulator introduced in this part. Suppose that in (9) the nonlinearity term defined by the following term

$$
\begin{aligned}
& N(\boldsymbol{q}, \dot{q})=B(q) \dot{q} \dot{q}+C(q) \dot{q}^{2}+g(q)= \\
& {\left[\begin{array}{c}
b_{112} \dot{\boldsymbol{q}}_{1} \dot{\boldsymbol{q}}_{2}+\boldsymbol{b}_{113} \dot{\boldsymbol{q}}_{1} \dot{\boldsymbol{q}}_{3}+\mathbf{0}+\boldsymbol{b}_{123} \dot{\boldsymbol{q}}_{2} \dot{\boldsymbol{q}}_{3} \\
\mathbf{0}+\boldsymbol{b}_{223} \dot{\boldsymbol{q}}_{2} \dot{\boldsymbol{q}}_{3}+\mathbf{0}+\mathbf{0} \\
\mathbf{0} \\
\boldsymbol{b}_{\mathbf{4 1 2}} \dot{\boldsymbol{q}}_{1} \dot{\boldsymbol{q}}_{2}+\boldsymbol{b}_{\mathbf{4 1 3}} \dot{\boldsymbol{q}}_{1} \dot{\boldsymbol{q}}_{3}+\mathbf{0}+\mathbf{0} \\
\mathbf{0} \\
\mathbf{0}
\end{array}\right]+} \\
& {\left[\begin{array}{c}
C_{12} \dot{q}_{2}{ }^{2}+C_{13} \dot{q}_{3}{ }^{2} \\
C_{21} \dot{q}_{1}{ }^{2}+C_{23} \dot{q}_{3}{ }^{2} \\
C_{31} \dot{q}_{1}{ }^{2}+C_{32} \dot{q}_{2}{ }^{2} \\
0 \\
C_{51} \dot{q}_{1}{ }^{2}+C_{52} \dot{q}_{2}{ }^{2} \\
0
\end{array}\right]+\left[\begin{array}{c}
0 \\
g_{2} \\
g_{3} \\
0 \\
g_{5} \\
0
\end{array}\right]}
\end{aligned}
$$

Therefore the equation of PD-CTC for control of PUMA telemanipulator is written as the equation of (12);

$$
\begin{aligned}
& {\left[\begin{array}{l}
\widehat{\tau_{1}} \\
\widehat{\tau_{2}} \\
\widehat{\tau_{3}} \\
\widehat{\tau_{4}} \\
\widehat{\tau_{5}} \\
\widehat{\tau_{6}}
\end{array}\right]} \\
& =\left[\begin{array}{cccccc}
M_{11} & M_{12} & M_{13} & 0 & 0 & 0 \\
M_{21} & M_{22} & M_{23} & 0 & 0 & 0 \\
M_{31} & M_{32} & M_{33} & 0 & M_{35} & 0 \\
0 & 0 & 0 & M_{44} & 0 & 0 \\
0 & 0 & 0 & 0 & M_{55} & 0 \\
0 & 0 & 0 & 0 & 0 & M_{66}
\end{array}\right] \\
& {\left[\begin{array}{l}
\ddot{q}_{d 1}+K_{v 1} \dot{e}_{1}+K_{p 1} e_{1} \\
\ddot{q}_{d 2}+K_{v 2} \dot{e}_{2}+K_{p 2} e_{2} \\
\ddot{q}_{d 3}+K_{v 3} \dot{e}_{3}+K_{p 3} e_{3} \\
\ddot{q}_{d 4}+K_{v 4} \dot{e}_{4}+K_{p 4} e_{4} \\
\ddot{q}_{d 5}+K_{v 5} \dot{e}_{5}+K_{p 5} e_{5} \\
\ddot{q}_{d 6}+K_{v 6} \dot{e}_{6}+K_{p 6} e_{6}
\end{array}\right]} \\
& +\left[\begin{array}{c}
b_{112} \dot{q}_{1} \dot{q}_{2}+b_{113} \dot{q}_{1} \dot{q}_{3}+0+b_{123} \dot{q}_{2} \dot{q} \\
0+b_{223} \dot{q}_{2} \dot{q}_{3}+0+0 \\
0 \\
b_{412} \dot{q}_{1} \dot{q}_{2}+b_{413} \dot{q}_{1} \dot{q}_{3}+0+0 \\
0 \\
0
\end{array}\right.
\end{aligned}
$$




$$
\left[\begin{array}{c}
C_{12} \dot{q}_{2}{ }^{2}+C_{13} \dot{q}_{3}{ }^{2} \\
C_{21} \dot{q}_{1}{ }^{2}+C_{23} \dot{q}_{3}{ }^{2} \\
C_{31} \dot{q}_{1}{ }^{2}+C_{32} \dot{q}_{2}{ }^{2} \\
0 \\
C_{51} \dot{q}_{1}{ }^{2}+C_{52} \dot{q}_{2}{ }^{2} \\
0
\end{array}\right]+\left[\begin{array}{c}
0 \\
g_{2} \\
g_{3} \\
0 \\
g_{5} \\
0
\end{array}\right]
$$

The controller based on a formulation (12) is related to robot dynamics therefore it has problems in uncertain conditions.

\subsection{Intro to Switching Sliding Mode Methodology:}

Design a robust controller for robot manipulator is essential because robot manipulator has highly nonlinear dynamic parameters. In this section formulations of sliding mode controller for robot manipulator is presented based on [13-24]. Consider a nonlinear single input dynamic system is defined by:

$$
x^{(n)}=f(\vec{x})+b(\vec{x}) u
$$

Where $\mathrm{u}$ is the vector of control input, $\boldsymbol{x}^{(\boldsymbol{n})}$ is the $\boldsymbol{n}^{\boldsymbol{t h}}$ derivation of $x, x=\left[x, \dot{x}, \ddot{x}, \ldots, x^{(n-1)}\right]^{T}$ is the state vector, $\boldsymbol{f}(\boldsymbol{x})$ is unknown or uncertainty, and $\boldsymbol{b}(\boldsymbol{x})$ is of known sign function. The main goal to design this controller is train to the desired state; $\boldsymbol{x}_{\boldsymbol{d}}=$ $\left[x_{d}, \dot{x}_{d}, \ddot{x}_{d}, \ldots, x_{d}^{(n-1)}\right]^{T}$, and trucking error vector is defined by;

$$
\widetilde{x}=x-x_{d}=\left[\widetilde{x}, \ldots, \widetilde{x}^{(n-1)}\right]^{T}
$$

A time-varying sliding surface $\boldsymbol{s}(\boldsymbol{x}, \boldsymbol{t})$ in the state space $\boldsymbol{R}^{\boldsymbol{n}}$ is given by;

$$
s(x, t)=\left(\frac{d}{d t}+\lambda\right)^{n-1} \tilde{x}=0
$$

where $\lambda$ is the positive constant. To further penalize tracking error, integral part can be used in sliding surface part as follows;

$$
\boldsymbol{s}(\boldsymbol{x}, \boldsymbol{t})=\left(\frac{d}{d t}+\lambda\right)^{n-1}\left(\int_{0}^{t} \tilde{\boldsymbol{x}} \boldsymbol{d t}\right)=\mathbf{0}
$$

The main target in this methodology is kept the sliding surface slope $\boldsymbol{s}(\boldsymbol{x}, \boldsymbol{t})$ near to the zero. Therefore, one of the common strategies is to find input $\boldsymbol{U}$ outside of $\boldsymbol{s}(\boldsymbol{x}, \boldsymbol{t})$;

$$
\frac{1}{2} \frac{d}{d t} s^{2}(x, t) \leq-\zeta|s(x, t)|
$$

where $\zeta$ is positive constant.

$$
\text { If } \mathbf{S}(\mathbf{0})>\mathbf{0} \rightarrow \frac{\mathrm{d}}{\mathrm{dt}} \mathbf{S}(\mathrm{t}) \leq-\zeta
$$

To eliminate the derivative term, it is used an integral term from $\mathrm{t}=0$ to $\mathrm{t}=\boldsymbol{t}_{\text {reach }}$

$$
\begin{aligned}
& \int_{t=0}^{t=t_{\text {reach }}} \frac{d}{d t} S(t) \leq-\int_{t=0}^{t=t_{\text {reach }}} \eta \rightarrow \\
& S\left(t_{\text {reach }}\right)-S(0) \leq-\zeta\left(t_{\text {reach }}-0\right)
\end{aligned}
$$

Where $t_{\text {reach }}$ is the time that trajectories reach to the sliding surface so, suppose $\mathrm{S}\left(t_{\text {reach }}=0\right)$ defined as

$$
0-S(0) \leq-\eta\left(t_{\text {reach }}\right) \rightarrow t_{\text {reach }} \leq \frac{S(0)}{\zeta}
$$

and

$$
\begin{aligned}
& \text { if } \boldsymbol{S}(0)<0 \rightarrow 0-S(0) \leq-\eta\left(\boldsymbol{t}_{\text {reach }}\right) \rightarrow \\
& \boldsymbol{S}(\mathbf{0}) \leq-\zeta\left(\boldsymbol{t}_{\text {reach }}\right) \rightarrow \boldsymbol{t}_{\text {reach }} \leq \frac{|\boldsymbol{S}(\mathbf{0})|}{\eta}
\end{aligned}
$$

Equation (20) guarantees time to reach the sliding surface is smaller than $\frac{|\boldsymbol{S}(\mathbf{0})|}{\zeta}$ since the trajectories are outside of $S(t)$.

$$
\text { if } S_{t_{\text {reach }}}=S(0) \rightarrow \operatorname{error}\left(x-x_{d}\right)=0
$$

suppose $\mathrm{S}$ is defined as

$$
\begin{aligned}
& s(x, t)=\left(\frac{d}{d t}+\lambda\right) \quad \widetilde{x}=\left(\dot{\mathbf{x}}-\dot{\mathbf{x}}_{\mathbf{d}}\right)+ \\
& \lambda\left(\mathbf{x}-\mathbf{x}_{\mathbf{d}}\right)
\end{aligned}
$$

The derivation of $\mathrm{S}$, namely, $\dot{S}$ can be calculated as the following;

$$
\dot{S}=\left(\ddot{\mathbf{x}}-\ddot{\mathbf{x}}_{\mathbf{d}}\right)+\lambda\left(\dot{\mathbf{x}}-\dot{\mathbf{x}}_{\mathbf{d}}\right)
$$

\subsection{Fuzzy Inference Engine:}

This section provides a review about foundation of fuzzy logic based on $[32,53]$. Supposed that $U$ is the universe of discourse and $x$ is the element of $U$, therefore, a crisp set can be defined as a set which consists of different elements $(x)$ will all or no membership in a set. A fuzzy set is a set that each element has a membership grade, therefore it can be written by the following definition;

$$
A=\left\{x, \mu_{A}(x) \mid x \in X\right\} ; A \in U
$$

Where an element of universe of discourse is $x, \mu_{A}$ is the membership function (MF) of fuzzy set. The membership function $\left(\mu_{A}(x)\right)$ of fuzzy set $A$ must have a value between zero and one. If the membership function $\mu_{A}(x)$ value equal to zero or one, this set change to a crisp set but if it has a value between zero and one, it is a fuzzy set. Defining membership function for fuzzy sets has divided into two main groups; namely; numerical and functional method, which in numerical 
method each number has different degrees of membership function and functional method used standard functions in fuzzy sets. The membership function which is often used in practical applications includes triangular form, trapezoidal form, bell-shaped form, and Gaussian form.

Linguistic variable can open a wide area to use of fuzzy logic theory in many applications (e.g., control and system identification). In a natural artificial language all numbers replaced by words or sentences.

If - then Rule statements are used to formulate the condition statements in fuzzy logic. A single fuzzy If - then rule can be written by

\section{If $x$ is $A$ Then $y$ is $B$}

where $A$ and $B$ are the Linguistic values that can be defined by fuzzy set, the If - part of the part of " $x$ is $A$ " is called the antecedent part and the thenpart of the part of " $y$ is $B$ " is called the Consequent or Conclusion part. The antecedent of a fuzzy if-then rule can have multiple parts, which the following rules shows the multiple antecedent rules:

\section{if $e$ is $N B$ and $\dot{e}$ is ML then $T$ is $L L$}

where $e$ is error, $\dot{e}$ is change of error, $N B$ is Negative Big, $M L$ is Medium Left, $T$ is torque and $L L$ is Large Left. If - then rules have three parts, namely, fuzzify inputs, apply fuzzy operator and apply implication method which in fuzzify inputs the fuzzy statements in the antecedent replaced by the degree of membership, apply fuzzy operator used when the antecedent has multiple parts and replaced by single number between 0 to 1 , this part is a degree of support for the fuzzy rule, and apply implication method used in consequent of fuzzy rule to replaced by the degree of membership. The fuzzy inference engine offers a mechanism for transferring the rule base in fuzzy set which it is divided into two most important methods, namely, Mamdani method and Sugeno method. Mamdani method is one of the common fuzzy inference systems and he designed one of the first fuzzy controllers to control of system engine. Mamdani's fuzzy inference system is divided into four major steps: fuzzification, rule evaluation, aggregation of the rule outputs and defuzzification. Michio Sugeno use a singleton as a membership function of the rule consequent part. The following definition shows the Mamdani and Sugeno fuzzy rule base

$$
\begin{aligned}
& \text { Mamdani F. } R^{1}: \text { if } \quad x \text { is } A \text { and } \\
& y \text { is } B \text { then } z \text { is } C \\
& \text { Sugeno } F . R^{1} \text { if } x \text { is } A \text { and } \\
& y \text { is } B \text { then } f(x, y) \text { is } C
\end{aligned}
$$

When $x$ and $y$ have crisp values fuzzification calculates the membership degrees for antecedent part. Rule evaluation focuses on fuzzy operation $(A N D / O R)$ in the antecedent of the fuzzy rules. The aggregation is used to calculate the output fuzzy set and several methodologies can be used in fuzzy logic controller aggregation, namely, Max-Min aggregation, Sum-Min aggregation, Max-bounded product, Max-drastic product, Max-bounded sum, Max-algebraic sum and Min-max. Two most common methods that used in fuzzy logic controllers are Max-min aggregation and Sum-min aggregation. Max-min aggregation defined as below

$$
\begin{aligned}
& \mu_{U}\left(x_{k}, y_{k}, U\right)=\mu_{\cup_{i=1}^{r} F R^{i}}\left(x_{k}, y_{k}, U\right) \\
& =\max \left\{\min _{i=1}^{r}\left[\mu_{R_{p q}}\left(x_{k}, y_{k}\right), \mu_{p_{m}}(U)\right]\right\}
\end{aligned}
$$

The Sum-min aggregation defined as below

$$
\begin{aligned}
& \mu_{U}\left(x_{k}, y_{k}, U\right)=\mu_{\cup_{i=1}^{r} F R^{i}}\left(x_{k}, y_{k}, U\right) \\
& =\sum \min _{i=1}^{r}\left[\mu_{R}\left(x_{k}, y_{k}\right), \mu_{p_{m}}(U)\right]
\end{aligned}
$$

where $r$ is the number of fuzzy rules activated by $x_{k}$ and $y_{k}$ and also $\mu_{\cup_{i=1}^{r} F R^{i}}\left(x_{k}, y_{k}, U\right)$ is a fuzzy interpretation of $i-t h$ rule. Defuzzification is the last step in the fuzzy inference system which it is used to transform fuzzy set to crisp set. Consequently defuzzification's input is the aggregate output and the defuzzification's output is a crisp number. Centre of gravity method (COG) and Centre of area method $(C O A)$ are two most common defuzzification methods, which $C O G$ method used the following equation to calculate the defuzzification

$$
\operatorname{COG}\left(x_{k}, y_{k}\right)=\frac{\sum_{i} U_{i} \sum_{j=1}^{r} \cdot \mu_{u}\left(x_{k}, y_{k}, U_{i}\right)}{\sum_{i} \sum_{j=1}^{r} \cdot \mu_{u}\left(x_{k}, y_{k}, U_{i}\right)}
$$

and $C O A$ method used the following equation to calculate the defuzzification

$$
\operatorname{COA}\left(x_{k}, y_{k}\right)=\frac{\sum_{i} U_{i} \cdot \mu_{u}\left(x_{k}, y_{k}, U_{i}\right)}{\sum_{i} \mu_{U} \cdot\left(x_{k}, y_{k}, U_{i}\right)}
$$

Where $\operatorname{COG}\left(x_{k}, y_{k}\right)$ and $\operatorname{COA}\left(x_{k}, y_{k}\right)$ illustrates the crisp value of defuzzification output, $U_{i} \in U$ is discrete element of an output of the fuzzy set, $\mu_{U} \cdot\left(x_{k}, y_{k}, U_{i}\right)$ is the fuzzy set membership function, and $r$ is the number of fuzzy rules.

Based on foundation of fuzzy logic methodology; fuzzy logic controller has played important rule to design nonlinear controller for nonlinear and uncertain systems [53]. However the application area for fuzzy control is really wide, the basic form for all command types of controllers consists of;

- Input fuzzification (binary-to-fuzzy[B/F]conversion)

- Fuzzy rule base (knowledge base)

- Inference engine

- Output defuzzification (fuzzy-to-binary 


\section{Methodology}

\subsection{Computed Sliding Switching Torque Like Method}

This part is focused on applied sliding switching method in computed torque controller to increased stability of the main controller. Switching sliding mode methodology is a nonlinear robust and stable controller and computed torque controller is a nonlinear controller but it has a challenge in stability and robustness especially in presence of uncertainty and disturbance. Based on literature CTC formulation is written by;

$$
\tau=M(q)\left(\ddot{q}_{d}+K_{v} \dot{e}+K_{p} e\right)+N(q, \dot{q})
$$

The sliding surface formulation and the rate of sliding surface formulation are calculated by;

$$
\begin{aligned}
& s(x, t)=\left(\frac{d}{d t}+\lambda\right) \quad \widetilde{x}=\left(\dot{\mathbf{x}}-\dot{\mathbf{x}}_{\mathrm{d}}\right)+ \\
& \lambda\left(\mathrm{x}-\mathbf{x}_{\mathbf{d}}\right) \\
& \dot{S}=\left(\ddot{\mathbf{x}}-\ddot{\mathbf{x}}_{\mathrm{d}}\right)+\lambda\left(\dot{\mathbf{x}}-\dot{\mathbf{x}}_{\mathbf{d}}\right)
\end{aligned}
$$

To improve the stability based on LYAPUNOV formulation sliding surface formulation and derivative of it applied to CTC based on following formulation;

$$
\begin{gathered}
\tau=M(q) \times \operatorname{sgn}\left(\ddot{q}_{d}+K_{v}\left(\left(\ddot{\mathbf{x}}-\ddot{\mathbf{x}}_{\mathrm{d}}\right)+\right.\right. \\
\left.\lambda\left(\dot{\mathbf{x}}-\dot{\mathbf{x}}_{\mathrm{d}}\right)\right)+K_{p}\left(\left(\dot{\mathbf{x}}-\dot{\mathbf{x}}_{\mathrm{d}}\right)+\lambda(\mathbf{x}-\right. \\
\left.\left.\left.\mathbf{x}_{\mathrm{d}}\right)\right)\right)+N(\boldsymbol{q}, \dot{q})
\end{gathered}
$$

To resolve uncertain problem this research is focused on to design SISO sliding mode switching computed torque like methodology. The firs type of fuzzy systems is given by

$$
f(x)=\sum_{l=1}^{M} \theta^{l} \mathcal{E}^{l}(x)=\theta^{T} \mathcal{E}(x)
$$

Where

$\theta=\left(\theta^{1}, \ldots, \theta^{M}\right)^{T}, \mathcal{E}(x)=$ $\left(\mathcal{E}^{1}(x), \ldots, \mathcal{E}^{M}(x)\right)^{T}$, and $\mathcal{E}^{l}(x)=$ $: \prod_{i=1}^{n} \frac{\mu_{A_{i}^{l}}\left(x_{i}\right)}{m} \sum_{l=1}^{M}\left(\prod_{i=1}^{n} \mu_{A_{i}^{l}}\left(x_{i}\right)\right) . \quad \theta^{1}, \ldots, \theta^{M} \quad$ are adjustable parameters in (37). $\mu_{A_{1}^{1}}\left(x_{1}\right), \ldots, \mu_{A_{n}^{m}}\left(x_{n}\right)$ are given membership functions whose parameters will not change over time.

The second type of fuzzy systems is given by

$$
=\frac{\sum_{l=1}^{M} \theta^{l}\left[\prod_{i=1}^{n} \exp \left(-\left(\frac{x_{i}-\alpha_{i}^{l}}{\delta_{i}^{l}}\right)^{2}\right)\right]}{\sum_{l=1}^{M}\left[\prod_{i=1}^{n} \exp \left(-\left(\frac{x_{i}-\alpha_{i}^{l}}{\delta_{i}^{l}}\right)^{2}\right)\right]}
$$

Where $\theta^{l}, \alpha_{i}^{l}$ and $\delta_{i}^{l}$ are all adjustable parameters. From the universal approximation theorem, we know that we can find a fuzzy system to estimate any continuous function. For the first type of fuzzy systems, we can only adjust $\theta^{l}$ in (37). We define $f^{\wedge}(x \mid \theta)$ as the approximator of the real function $f(x)$.

$$
f^{\wedge}(x \mid \theta)=\theta^{T} \varepsilon(x)
$$

We define $\theta^{*}$ as the values for the minimum error:

$$
\theta^{*}=\arg \min _{\theta \in \Omega}\left[\sup _{x \in U}\left|f^{\wedge}(x \mid \theta)-g(x)\right|\right]
$$

Where $\Omega$ is a constraint set for $\theta$. For specific $x, \sup _{x \in U}\left|f^{\wedge}\left(x \mid \theta^{*}\right)-f(x)\right|$ is the minimum approximation error we can get. We used the first type of fuzzy systems (38) to estimate the nonlinear system (11) the fuzzy formulation can be write as below;

$$
\begin{aligned}
\boldsymbol{f}(\boldsymbol{x} \mid \boldsymbol{\theta}) & =\boldsymbol{\theta}^{T} \boldsymbol{\varepsilon}(\boldsymbol{x}) \\
& =\frac{\sum_{l=1}^{n} \boldsymbol{\theta}^{l}\left[\boldsymbol{\mu}_{A^{l}}(\boldsymbol{x})\right]}{\sum_{l=1}^{n}\left[\boldsymbol{\mu}_{A^{l}}(\boldsymbol{x})\right]}
\end{aligned}
$$

Where $\theta^{1}, \ldots, \theta^{n}$ are adjusted by an adaptation law. The general SISO if-then rules are given by

$$
\begin{gathered}
R^{l} \text { : if } x_{1} \text { is } A_{1}^{l}, x_{2} \text { is } A_{2}^{l}, \ldots, x_{n} \text { is } A_{n}^{l} \\
\text {, then } y_{1} \text { is } B_{1}^{l}, \ldots, y_{m} \text { is } B_{m}^{l}
\end{gathered}
$$

Where $l=1,2, \ldots, M$ are fuzzy if-then rules; $x=$ $\left(x_{1}, \ldots, x_{n}\right)^{T}$ and $y=\left(y_{1}, \ldots, y_{n}\right)^{T}$ are the input and output vectors of the fuzzy system. The SISO fuzzy system is define as

$$
f(x)=\ominus^{T} \varepsilon(x)
$$

Where

$$
\begin{gathered}
\ominus^{\boldsymbol{T}}=\left(\boldsymbol{\theta}_{\mathbf{1}}, \ldots, \boldsymbol{\theta}_{\boldsymbol{m}}\right)^{\boldsymbol{T}}=\left[\begin{array}{c}
\boldsymbol{\theta}_{\mathbf{1}}^{\mathbf{1}}, \boldsymbol{\theta}_{\mathbf{1}}^{\mathbf{2}}, \ldots, \boldsymbol{\theta}_{\mathbf{1}}^{\boldsymbol{M}} \\
\boldsymbol{\theta}_{\mathbf{2}}^{\mathbf{1}}, \boldsymbol{\theta}_{\mathbf{2}}^{\mathbf{2}}, \ldots, \boldsymbol{\theta}_{\mathbf{2}}^{\boldsymbol{M}} \\
\vdots \\
\boldsymbol{\theta}_{\boldsymbol{m}}^{\mathbf{1}}, \boldsymbol{\theta}_{\boldsymbol{m}}^{\mathbf{2}}, \ldots, \boldsymbol{\theta}_{\boldsymbol{m}}^{\boldsymbol{M}}
\end{array}\right] \\
\varepsilon(x)=\left(\varepsilon^{1}(x), \ldots, \varepsilon^{M}(x)\right)^{T}, \varepsilon^{1}(x)=\prod_{i=1}^{n} \mu_{A_{i}^{l}}\left(x_{i}\right) / \\
\sum_{l=1}^{M}\left(\prod_{i=1}^{n} \mu_{A_{i}^{l}}\left(x_{i}\right)\right), \text { and } \mu_{A_{i}^{l}}\left(x_{i}\right) \text { is defined in }(32) . \text { To }
\end{gathered}
$$
reduce the number of fuzzy rules, we divide the fuzzy system in to three parts:

$$
\begin{aligned}
& \begin{aligned}
F^{1}(\boldsymbol{q}, \dot{\boldsymbol{q}}) & =\ominus^{1^{T}} \varepsilon(\boldsymbol{q}, \dot{\boldsymbol{q}}) \\
& =\left[\boldsymbol{\theta}_{1}^{1^{T}} \varepsilon(\boldsymbol{q}, \dot{\boldsymbol{q}}), \ldots, \boldsymbol{\theta}_{m}^{\mathbf{1}^{T}} \boldsymbol{T}(\boldsymbol{q}, \dot{\boldsymbol{q}})\right]^{T}
\end{aligned} \\
& \boldsymbol{F}^{2}\left(\boldsymbol{q}, \ddot{\boldsymbol{q}}_{r}\right)=\ominus^{2^{T}} \varepsilon\left(\boldsymbol{q}, \ddot{\boldsymbol{q}}_{r}\right) \\
& =\left[\boldsymbol{\theta}_{1}^{2^{T}} \varepsilon\left(\boldsymbol{q}, \ddot{\boldsymbol{q}}_{r}\right), \ldots, \boldsymbol{\theta}_{m}{ }^{T} \varepsilon\left(\boldsymbol{q}, \ddot{\boldsymbol{q}}_{r}\right)\right]^{T}
\end{aligned}
$$




$$
\begin{aligned}
F^{3}(q, \ddot{q}) & =\ominus^{3^{T}} \varepsilon(q, \ddot{q}) \\
& =\left[\theta_{1}^{3^{T}} \varepsilon(q, \dot{q}), \ldots, \theta_{m}^{3^{T}} \varepsilon(q, \ddot{q})\right]^{T}
\end{aligned}
$$

The control security input is given by

$$
\begin{gathered}
\tau=M^{\wedge} \ddot{q}_{r}+B(\boldsymbol{q}) \dot{\boldsymbol{q}} \dot{q}+C(\boldsymbol{q}) \dot{\boldsymbol{q}}^{2}+ \\
g(\boldsymbol{q})+\boldsymbol{F}^{\mathbf{1}}(\boldsymbol{q}, \dot{\boldsymbol{q}})+\boldsymbol{F}^{\mathbf{2}}\left(\boldsymbol{q}, \ddot{\boldsymbol{q}}_{r}\right)+ \\
\boldsymbol{F}^{\mathbf{3}}(\boldsymbol{q}, \ddot{\boldsymbol{q}})-\operatorname{sgn}\left(\boldsymbol { K } _ { \boldsymbol { v } } \left(\left(\ddot{\mathbf{x}}-\ddot{\mathbf{x}}_{\mathbf{d}}\right)+\right.\right. \\
\left.\left.\lambda\left(\dot{\mathbf{x}}-\dot{\mathbf{x}}_{\mathbf{d}}\right)\right)+\boldsymbol{K}_{\boldsymbol{p}}\left(\left(\dot{\mathbf{x}}-\dot{\mathbf{x}}_{\mathrm{d}}\right)+\lambda\left(\mathbf{x}-\mathbf{x}_{\mathrm{d}}\right)\right)\right)
\end{gathered}
$$

Where $M^{\wedge}, \boldsymbol{B}(\boldsymbol{q}) \dot{\boldsymbol{q}} \dot{\boldsymbol{q}}, \boldsymbol{C}(\boldsymbol{q}) \dot{\boldsymbol{q}}^{2}, \boldsymbol{g}(\boldsymbol{q})$ are the estimations of $M(q)$. This system is stable which the stability proof is given in the following formulas;

$$
\begin{aligned}
\dot{\theta}_{j}^{1} & =-\Gamma_{1 j} s_{j} \varepsilon(q, \dot{q}) \\
\dot{\theta}_{j}^{2} & =-\Gamma_{2 j} s_{j} \varepsilon\left(q, \ddot{q}_{r}\right) \\
\dot{\theta}_{j}^{3} & =-\Gamma_{3 j} s_{j} \varepsilon(q, \ddot{q})
\end{aligned}
$$

Where $j=1, \ldots, m$ and $\Gamma_{1 j}-\Gamma_{3 j}$ are positive diagonal matrices.

The Lyapunov function candidate is presented as

$$
\begin{aligned}
& V=\frac{1}{2} s^{T} M s+\frac{1}{2} \sum_{j=1}^{m} \frac{1}{\Gamma_{1 j}} \emptyset_{j}^{1^{T}} \emptyset_{j}^{1}+ \\
& \frac{1}{2} \sum_{j=1}^{m} \frac{1}{\Gamma_{2 j}} \emptyset_{j}^{2^{T}} \emptyset_{j}^{2}+\frac{1}{2} \sum_{j=1}^{m} \frac{1}{\Gamma_{3 j}} \emptyset_{j}^{13^{T}} \emptyset_{j}^{3}
\end{aligned}
$$

Where $\emptyset_{j}^{1}=\emptyset_{j}^{1^{*}}-\emptyset_{j}^{1}, \emptyset_{j}^{2}=\emptyset_{j}^{2^{*}}-\emptyset_{j}^{2}$ and $\emptyset_{j}^{3}=$ $\emptyset_{j}^{3^{*}}-\emptyset_{j}^{3}$ we define

$$
F\left(q, \dot{q}, \ddot{q}_{r}, \ddot{q}\right)=\underset{F^{3}(q, \ddot{q})}{F^{1}(q, \dot{q})+F^{2}\left(q, \ddot{q}_{r}\right)+}
$$

From (26) and (27), we get

$$
\begin{gathered}
M(\boldsymbol{q}) \ddot{\boldsymbol{q}}+B(\boldsymbol{q}) \dot{\boldsymbol{q}} \dot{\boldsymbol{q}}+\boldsymbol{C}(\boldsymbol{q}) \dot{\boldsymbol{q}}^{2}+\boldsymbol{g}(\boldsymbol{q})= \\
\boldsymbol{M}^{\wedge} \ddot{\boldsymbol{q}} \boldsymbol{r}+\boldsymbol{B}(\boldsymbol{q}) \dot{\boldsymbol{q}} \dot{\boldsymbol{q}}+\widehat{C(\boldsymbol{q})} \dot{\boldsymbol{q}}^{2}+\boldsymbol{g}(\boldsymbol{q})+ \\
\boldsymbol{F}\left(\boldsymbol{q}, \dot{\boldsymbol{q}}, \ddot{\boldsymbol{q}}_{r}, \ddot{\boldsymbol{q}}\right)-K_{D} \boldsymbol{s}-W \operatorname{sgn}(\boldsymbol{s})
\end{gathered}
$$

Since $\dot{q}_{r}=\dot{q}-s$ and $\ddot{q}_{r}=\ddot{q}-\dot{s}$, we get

$$
\begin{gathered}
M \dot{s}+\left(B(\boldsymbol{q}) \dot{\boldsymbol{q}} \dot{\boldsymbol{q}}+\boldsymbol{C}(\boldsymbol{q}) \dot{\boldsymbol{q}}^{2}+\boldsymbol{g}(\boldsymbol{q})+\right. \\
\left.K_{D}\right) s+W \operatorname{sgn}(\boldsymbol{s})=-\Delta \boldsymbol{F}+\boldsymbol{F}\left(\boldsymbol{q}, \dot{\boldsymbol{q}}, \ddot{\boldsymbol{q}}_{r}, \ddot{\boldsymbol{q}}\right)
\end{gathered}
$$

Then $M \dot{s}+\boldsymbol{B}(\boldsymbol{q}) \dot{\boldsymbol{q}} \dot{\boldsymbol{q}}+\boldsymbol{C}(\boldsymbol{q}) \dot{\boldsymbol{q}}^{2}+\boldsymbol{g}(\boldsymbol{q}) s$ can be written as

$$
\begin{gathered}
M \dot{s}+B(q) \dot{q} \dot{q}+C(q) \dot{q}^{2}+g(q) s= \\
-\Delta F+F\left(q, \dot{q}, \ddot{q}_{r}, \ddot{q}\right)-K_{D} s-W \operatorname{sgn}(s)
\end{gathered}
$$

Where $\quad \Delta F=\widetilde{M} \ddot{q}_{r}+\boldsymbol{B}(\boldsymbol{q}) \dot{\boldsymbol{q}} \dot{\boldsymbol{q}}+\boldsymbol{C}(\boldsymbol{q}) \dot{\boldsymbol{q}}^{2}+$ $\boldsymbol{g}(\boldsymbol{q}), \widetilde{M}=M-M^{\wedge}, \tilde{C}_{1}=\boldsymbol{B}(\boldsymbol{q}) \dot{\boldsymbol{q}} \dot{\boldsymbol{q}}+\boldsymbol{C}(\boldsymbol{q}) \dot{\boldsymbol{q}}^{2}+$ $\boldsymbol{g}(\boldsymbol{q})-\boldsymbol{B}(\boldsymbol{q}) \dot{\boldsymbol{q}} \dot{\boldsymbol{q}}+\widetilde{\boldsymbol{C}(\boldsymbol{q})} \dot{\boldsymbol{q}}^{2}+\boldsymbol{g}(\boldsymbol{q})$ The derivative of $V$ is

$$
\dot{V}=s^{T} M \dot{s}+\frac{1}{2} s^{T} \dot{M} s+\sum_{j=1}^{m} \frac{1}{\Gamma_{1 j}} \emptyset_{j}^{1^{T}} \dot{\emptyset}_{j}^{1}+
$$

$$
\sum_{j=1}^{m} \frac{1}{\Gamma_{2 j}} \phi_{j}^{2^{T}} \dot{\emptyset}_{j}^{2}+\sum_{j=1}^{m} \frac{1}{\Gamma_{3 j}} \emptyset_{j}^{13^{T}} \dot{\phi}_{j}^{3}
$$

We know that $s^{T} M \dot{s}+\frac{1}{2} s^{T} \dot{M} s=s^{T}(M \dot{s}+$ $\left.\boldsymbol{B}(\boldsymbol{q}) \dot{\boldsymbol{q}} \dot{\boldsymbol{q}}+\boldsymbol{C}(\boldsymbol{q}) \dot{\boldsymbol{q}}^{2}+\boldsymbol{g}(\boldsymbol{q}) s\right)$ from (64). Then

$$
\begin{gathered}
\dot{V}=-s^{T}\left[-K_{D} s+W \operatorname{sgn}(s)+\Delta F-\right. \\
\left.F\left(q, \dot{q}, \ddot{q}_{r}, \ddot{q}\right)\right]+\sum_{j=1}^{m} \frac{1}{\Gamma_{1 j}} \phi_{j}^{1^{T}} \dot{\emptyset}_{j}^{1}+ \\
\sum_{j=1}^{m} \frac{1}{\Gamma_{2 j}} \phi_{j}^{2^{T}} \dot{\phi}_{j}^{2}+\sum_{j=1}^{m} \frac{1}{\Gamma_{3 j}} \phi_{j}^{13^{T}} \dot{\emptyset}_{j}^{3}
\end{gathered}
$$

We define the minimum approximation error as

$$
\begin{gathered}
\boldsymbol{\omega}= \\
\Delta \boldsymbol{F}-\left[\boldsymbol{F}^{\mathbf{1}}\left(\boldsymbol{q}, \dot{\boldsymbol{q}} \mid \ominus^{\mathbf{1}^{*}}\right)+\boldsymbol{F}^{\mathbf{2}}\left(\boldsymbol{q}, \ddot{\boldsymbol{q}}_{\boldsymbol{r}} \mid \ominus^{2^{*}}\right)+\right. \\
\left.\boldsymbol{F}^{\mathbf{3}}\left(\boldsymbol{q}, \ddot{\boldsymbol{q}} \mid \ominus^{3^{*}}\right)\right]
\end{gathered}
$$

We plug (65) in to (66)

$$
\begin{aligned}
& \dot{V}=-s^{T}\left[-K_{D} s+\right. \\
& W \operatorname{sgn}(s)+\Delta F- \\
& \left.\boldsymbol{F}\left(\boldsymbol{q}, \dot{\boldsymbol{q}}, \ddot{\boldsymbol{q}}_{r}, \ddot{\boldsymbol{q}}\right)\right]+ \\
& \sum_{j=1}^{m} \frac{1}{\Gamma_{1 j}} \emptyset_{j}^{1^{T}} \dot{\emptyset}_{j}^{1}+ \\
& \sum_{j=1}^{m} \frac{1}{\Gamma_{2 j}} \emptyset_{j}^{2^{T}} \dot{\phi}_{j}^{2}+ \\
& \sum_{j=1}^{m} \frac{1}{\Gamma_{3 j}} \phi_{j}^{13^{T}} \dot{\emptyset}_{j}^{3} \\
& =-s^{T}\left[-K_{D} s+W \operatorname{sgn}(s)+\omega+\right. \\
& \boldsymbol{F}^{\mathbf{1}}\left(\boldsymbol{q}, \dot{\boldsymbol{q}} \mid \ominus^{\mathbf{1}^{*}}\right)+\boldsymbol{F}^{\mathbf{2}}\left(\boldsymbol{q}, \ddot{\boldsymbol{q}}_{r} \mid \ominus^{\mathbf{2}^{*}}\right)+ \\
& \boldsymbol{F}^{\mathbf{3}}\left(\boldsymbol{q}, \ddot{\boldsymbol{q}} \mid \ominus^{3^{*}}\right)-\boldsymbol{F}^{\mathbf{1}}(\boldsymbol{q}, \dot{\boldsymbol{q}})+\boldsymbol{F}^{\mathbf{2}}\left(\boldsymbol{q}, \ddot{\boldsymbol{q}}_{r}\right)+ \\
& \left.F^{3}(q, \ddot{q})\right]+\sum_{j=1}^{m} \frac{1}{\Gamma_{1 j}} \emptyset_{j}^{1^{T}} \dot{\emptyset}_{j}^{1}+ \\
& \sum_{j=1}^{m} \frac{1}{\Gamma_{2 j}} \emptyset_{j}^{2^{T}} \dot{\emptyset}_{j}^{2}+\sum_{j=1}^{m} \frac{1}{\Gamma_{3 j}} \emptyset_{j}^{13^{T}} \dot{\emptyset}_{j}^{3} \\
& -s^{T} K_{D} s-s^{T} W \operatorname{sgn}(s)-s^{T} \omega- \\
& \sum_{j=1}^{m} s_{j} \emptyset_{j}^{1^{T}} \varepsilon(q, \dot{q})-\sum_{j=1}^{m} s_{j} \varnothing_{j}^{2^{T}} \varepsilon\left(q, \ddot{q}_{r}\right)- \\
& \sum_{j=1}^{m} s_{j} \phi_{j}^{3^{T}} \varepsilon(q, \ddot{q})+\sum_{j=1}^{m} \frac{1}{\Gamma_{1 j}} \phi_{j}^{1^{T}} \dot{\phi}_{j}^{1}+ \\
& \sum_{j=1}^{m} \frac{1}{\Gamma_{2 j}} \emptyset_{j}^{2^{T}} \dot{\emptyset}_{j}^{2}+\sum_{j=1}^{m} \frac{1}{\Gamma_{3 j}} \emptyset_{j}^{3^{T}} \dot{\emptyset}_{j}^{3} \\
& =-s^{T} K_{D} s-s^{T} W \operatorname{sgn}(s)- \\
& s^{T} \omega-\sum_{j=1}^{m} \emptyset_{j}^{1^{T}}\left(s_{j} \varepsilon(q, \dot{q})-\right. \\
& \left.\frac{1}{\Gamma_{1 j}} \dot{\phi}_{j}^{1}\right)- \\
& \sum_{j=1}^{m} \phi_{j}^{2^{T}}\left(s_{j} \varepsilon\left(q, \ddot{q}_{r}\right)-\right. \\
& \left.\frac{1}{\Gamma_{2 j}} \dot{\phi}_{j}^{2}\right)- \\
& \sum_{j=1}^{m} \emptyset_{j}^{3^{T}}\left(s_{j} \varepsilon\left(q, \ddot{q}_{r}\right)-\frac{1}{\Gamma_{3 j}} \dot{\emptyset}_{j}^{3}\right) \\
& =-s^{T} K_{D} s-s^{T} W \operatorname{sgn}(s)- \\
& s^{T} \omega-\sum_{j=1}^{m} \emptyset_{j}^{1^{T}}\left(s_{j} \varepsilon(q, \dot{q})+\right. \\
& \left.\frac{1}{\Gamma_{1 j}} \dot{\phi}_{j}^{1}\right)- \\
& \sum_{j=1}^{m} \phi_{j}^{2^{T}}\left(s_{j} \varepsilon\left(q, \ddot{q}_{r}\right)+\right. \\
& \left.\frac{1}{\Gamma_{2 j}} \dot{\phi}_{j}^{2}\right)- \\
& \sum_{j=1}^{m} \emptyset_{j}^{3^{T}}\left(s_{j} \varepsilon\left(q, \ddot{q}_{r}\right)+\frac{1}{\Gamma_{3 j}} \dot{\emptyset}_{j}^{3}\right)
\end{aligned}
$$


Then $\dot{V}$ becomes

$$
\begin{aligned}
\dot{V} & =-s^{T} K_{D} s-s^{T} W \operatorname{sgn}(s)-s^{T} \omega \\
& =-\sum_{j=1}^{m}\left(s_{j}^{2} K_{D j}+W_{j}\left|s_{j}\right|+s_{j} \omega_{j}\right) \\
& \left.=-\sum_{j=1}^{m}\left(s_{j}^{2} K_{D j}+W_{j}\left|s_{j}\right|+s_{j} \omega_{j}\right)\right]
\end{aligned}
$$

\section{Results}

To test the positioning error in proposed methodology three dimensions scope is used to show this factor. In this research trajectory following are compared in these two methods because it is very important to show the safety method in telemanipulator.

Circular Trajectory following by Telemanipulator: Figure 3 and 4 are shown the XYZ trajectory following in pure computed torque controller and artificial intelligence based sliding switching computed torque controller. Based on these two figures, proposed methodology has better performance to better enforcement of the order.

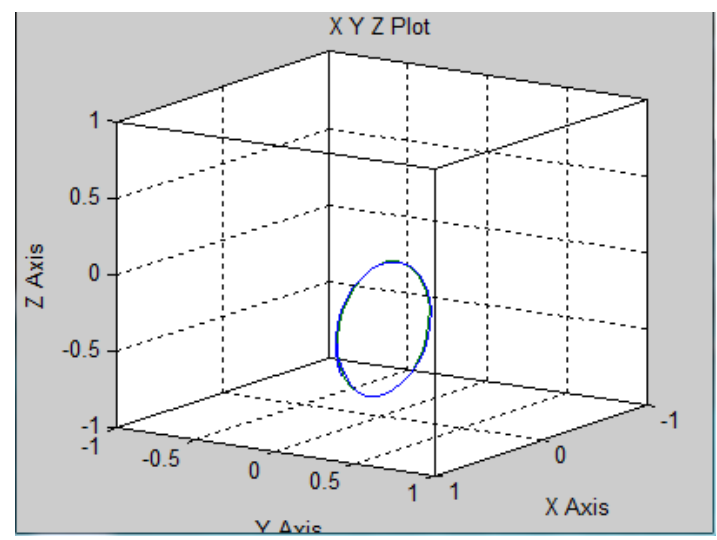

Fig. 3: Trajectory following by artificial intelligence based sliding switching computed torque controller applied to TELEMANIPULATOR

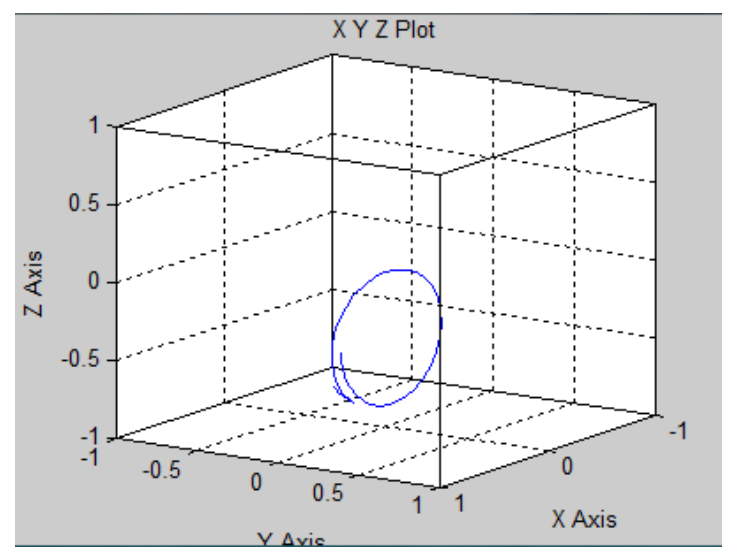

Fig. 4: Trajectory following by computed torque controller applied to TELEMANIPULATOR
By comparing response, Figure 3 and Figure 4, in two methods, proposed method has greater reliability. In medical science, reliability has played important role therefore proposed method used in TELEMANIPULATOR.

Error: The second problem that was observed with the robot is that after sending a motion command the joint angles would not move to the exact position but there would be an error associated with the new position. Error in joint angle position will be evident in any system but an analysis was conducted to verify that it would not effect the final position of the endoscopic manipulator to any considerable degree. Using the simulation environment, different motion commands were sent to the robot controller. The average error and maximum error in each joint angle was recorded and can be seen in Table 1.

Table 1: Average and Max error of proposed controller

\begin{tabular}{|c|c|c|c|}
\hline & Joint 1 & Joint 2 & Joint 3 \\
\hline Average error & 0.004953 & 0.003322 & 0.00165 \\
\hline Maximum error & 0.0104 & 0.0051 & 0.0038 \\
\hline
\end{tabular}

After it was known that the proposed methodology has minimal error associated with its positioning.

\section{Conclusion}

The main goal of this research was to design a robotic surgical system using an articulated arm for positioning an endoscopic tool. Additional goals were to create a new control methodology to an Intuitive Surgical EndoWrist. The system described is a demonstration of using a unique robot arm configuration to perform this motion however it is not intended for an actual surgical operation. Analysis of the system showed that repositioning the endoscopic manipulator is possible to within 0.05 inches. This algorithm was able to maintain the trocar point however error was observed during repositioning. This error is due to the robot arm actuation and presents itself as a limitation of the system. This research presents a unique artificial intelligence controllers technique for endoscopic surgery with precise localization and opens the door for several new and interesting future research topics.

\section{Acknowledgment}

The authors would like to thank the anonymous reviewers for their careful reading of this paper and for their helpful comments. This work was supported by the SSP Research and Development Corporation Program of Iran under grant no. 2012-Persian Gulf1A/A. 


\section{References}

[1] “Surgery.” WordNet Search - 2.1. Online.

[2] Wikipedia. Online.

[3] Stevens, Jason M., and Gregory D. Buckner. "Actuation and Control Strategies for Miniature Robotic Surgical Systems." Journal of Dynamic Systems, Measurement, and Control 127 (2005): 537-549.

[4] Griffin, R. Morgan. "Surgery Lite: Understanding Endoscopic Surgery." WebMD Feature 26 Oct. 2005

[5] Zenati, Marco. "Robotic Heart Surgery." Cardiology in Review 9.5 (2001): 287-294.

[6] Marohn, Michael R., and Eric J. Hanly. "TwentyFirst Century Surgery Using Twenty-First Century Technology: Surgical Robotics." Current Surgery 61.5 (2004): 466-473.

[7] Hanly, Eric J. "Multiservice Laparoscopic Surgical Training using the daVinci Surgical System." The American Journal of Surgery 187 (2004): 309-315.

[8] Ben-Porat, Ori, Moshe Shoham, and Joachim Meyer. "Control Design and Task Performance in Endoscopic Teleoperation.” Presence 9.3 (2000): 256-267.

[9] Dario, Paolo, Blake Hannaford, and Arianna Menciassi. "Smart Surgical Tools and Augmenting Devices." IEEE Transactions on Robotics and Automation 19.5 (2003): 782-792.

[10] Camarillo, David B., Thomas M. Krummel, and J. Kenneth Salisbury, Jr. Robotic Technology in Surgery: Past, Present, and Future." The American Journal of Surgery 188 (Suppl to Oct. 2004): 2S$15 \mathrm{~S}$.

[11] A. Vivas and V. Mosquera, "Predictive functional control of a PUMA robot," Conference Proceedings, 2005.

[12] D. Nguyen-Tuong, M. Seeger and J. Peters, "Computed torque control with nonparametric regression models," IEEE conference proceeding, 2008, pp. 212-217.

[13] Farzin Piltan , N. Sulaiman, Zahra Tajpaykar, Payman Ferdosali, Mehdi Rashidi, "Design Artificial Nonlinear Robust Controller Based on CTLC and FSMC with Tunable Gain," International Journal of Robotic and Automation, 2 (3): 205-220, 2011.

[14] Farzin Piltan, A. R. Salehi and Nasri B Sulaiman.," Design artificial robust control of second order system based on adaptive fuzzy gain scheduling," world applied science journal (WASJ), 13 (5): 1085-1092, 2011.

[15] Farzin Piltan, N. Sulaiman, Atefeh Gavahian, Samira Soltani, Samaneh Roosta, "Design
Mathematical Tunable Gain PID-Like Sliding Mode Fuzzy Controller with Minimum Rule Base," International Journal of Robotic and Automation, 2 (3): 146-156, 2011.

[16] Farzin Piltan , A. Zare, Nasri B. Sulaiman, M. H. Marhaban and R. Ramli, , "A Model Free Robust Sliding Surface Slope Adjustment in Sliding Mode Control for Telemanipulator," World Applied Science Journal, 12 (12): 2330-2336, 2011.

[17] Farzin Piltan , A. H. Aryanfar, Nasri B. Sulaiman, M. H. Marhaban and R. Ramli "Design Adaptive Fuzzy Robust Controllers for Robot Manipulator," World Applied Science Journal, 12 (12): 2317 2329, 2011.

[18] Farzin Piltan, N. Sulaiman , Arash Zargari, Mohammad Keshavarz, Ali Badri, "Design PIDLike Fuzzy Controller With Minimum Rule Base and Mathematical Proposed On-line Tunable Gain: Applied to Robot Manipulator," International Journal of Artificial intelligence and expert system, 2 (4):184-195, 2011.

[19] Farzin Piltan, Nasri Sulaiman, M. H. Marhaban and R. Ramli, "Design On-Line Tunable Gain Artificial Nonlinear Controller," Journal of Advances In Computer Research, 2 (4): 75-83, 2011.

[20] Farzin Piltan, N. Sulaiman, Payman Ferdosali, Iraj Assadi Talooki, “ Design Model Free Fuzzy Sliding Mode Control: Applied to Internal Combustion Engine," International Journal of Engineering, 5 (4):302-312, 2011.

[21] Farzin Piltan, N. Sulaiman, Samaneh Roosta, M.H. Marhaban, R. Ramli, "Design a New Sliding Mode Adaptive Hybrid Fuzzy Controller," Journal of Advanced Science \& Engineering Research , 1 (1): 115-123, 2011.

[22] Farzin Piltan, Atefe Gavahian, N. Sulaiman, M.H. Marhaban, R. Ramli, "Novel Sliding Mode Controller for robot manipulator using FPGA," Journal of Advanced Science \& Engineering Research, 1 (1): 1-22, 2011.

[23] Farzin Piltan, N. Sulaiman, A. Jalali \& F. Danesh Narouei, "Design of Model Free Adaptive Fuzzy Computed Torque Controller: Applied to Nonlinear Second Order System," International Journal of Robotics and Automation, 2 (4):232-244, 2011.

[24] Farzin Piltan, N. Sulaiman, Iraj Asadi Talooki, Payman Ferdosali, "Control of IC Engine: Design a Novel MIMO Fuzzy Backstepping Adaptive Based Fuzzy Estimator Variable Structure Control ," International Journal of Robotics and Automation, 2 (5):360-380, 2011.

[25] Farzin Piltan, N. Sulaiman, Payman Ferdosali, Mehdi Rashidi, Zahra Tajpeikar, “Adaptive MIMO 
Fuzzy Compensate Fuzzy Sliding Mode Algorithm: Applied to Second Order Nonlinear System," International Journal of Engineering, 5 (5): 380$398,2011$.

[26] Farzin Piltan, N. Sulaiman, Hajar Nasiri, Sadeq Allahdadi, Mohammad A. Bairami, "Novel Robot Manipulator Adaptive Artificial Control: Design a Novel SISO Adaptive Fuzzy Sliding Algorithm Inverse Dynamic Like Method," International Journal of Engineering, 5 (5): 399-418, 2011.

[27] Farzin Piltan, N. Sulaiman, Sadeq Allahdadi, Mohammadali Dialame, Abbas Zare, "Position Control of Robot Manipulator: Design a Novel SISO Adaptive Sliding Mode Fuzzy PD Fuzzy Sliding Mode Control," International Journal of Artificial intelligence and Expert System, 2 (5):208-228, 2011.

[28] Farzin Piltan, SH. Tayebi HAGHIGHI, N. Sulaiman, Iman Nazari, Sobhan Siamak, "Artificial Control of PUMA Robot Manipulator: A-Review of Fuzzy Inference Engine And Application to Classical Controller," International Journal of Robotics and Automation, 2 (5):401-425, 2011.

[29] Farzin Piltan, N. Sulaiman, Abbas Zare, Sadeq Allahdadi, Mohammadali Dialame, "Design Adaptive Fuzzy Inference Sliding Mode Algorithm: Applied to Robot Arm," International Journal of Robotics and Automation , 2 (5): 283-297, 2011.

[30] Farzin Piltan, Amin Jalali, N. Sulaiman, Atefeh Gavahian, Sobhan Siamak, "Novel Artificial Control of Nonlinear Uncertain System: Design a Novel Modified PSO SISO Lyapunov Based Fuzzy Sliding Mode Algorithm ," International Journal of Robotics and Automation, 2 (5): 298$316,2011$.

[31] Farzin Piltan, N. Sulaiman, Amin Jalali, Koorosh Aslansefat, "Evolutionary Design of Mathematical tunable FPGA Based MIMO Fuzzy Estimator Sliding Mode Based Lyapunov Algorithm: Applied to Robot Manipulator," International Journal of Robotics and Automation, 2 (5):317-343, 2011.

[32] Farzin Piltan, N. Sulaiman, Samaneh Roosta, Atefeh Gavahian, Samira Soltani, "Evolutionary Design of Backstepping Artificial Sliding Mode Based Position Algorithm: Applied to Robot Manipulator," International Journal of Engineering, 5 (5):419-434, 2011.

[33] Farzin Piltan, N. Sulaiman, S.Soltani, M. H. Marhaban \& R. Ramli, "An Adaptive sliding surface slope adjustment in PD Sliding Mode Fuzzy Control for Robot Manipulator," International Journal of Control and Automation , 4 (3): 65-76, 2011.
[34] Farzin Piltan, N. Sulaiman, Mehdi Rashidi, Zahra Tajpaikar, Payman Ferdosali, "Design and Implementation of Sliding Mode Algorithm: Applied to Robot Manipulator-A Review ," International Journal of Robotics and Automation, 2 (5):265-282, 2011.

[35] Farzin Piltan, N. Sulaiman, Amin Jalali, Sobhan Siamak, and Iman Nazari, "Control of Robot Manipulator: Design a Novel Tuning MIMO Fuzzy Backstepping Adaptive Based Fuzzy Estimator Variable Structure Control ," International Journal of Control and Automation, 4 (4):91-110, 2011.

[36] Farzin Piltan, N. Sulaiman, Atefeh Gavahian, Samaneh Roosta, Samira Soltani, "On line Tuning Premise and Consequence FIS: Design Fuzzy Adaptive Fuzzy Sliding Mode Controller Based on Lyaponuv Theory," International Journal of Robotics and Automation, 2 (5):381-400, 2011.

[37] Farzin Piltan, N. Sulaiman, Samaneh Roosta, Atefeh Gavahian, Samira Soltani, "Artificial Chattering Free on-line Fuzzy Sliding Mode Algorithm for Uncertain System: Applied in Robot Manipulator," International Journal of Engineering, 5 (5):360-379, 2011.

[38] Farzin Piltan, N. Sulaiman and I.AsadiTalooki, "Evolutionary Design on-line Sliding Fuzzy Gain Scheduling Sliding Mode Algorithm: Applied to Internal Combustion Engine," International Journal of Engineering Science and Technology, 3 (10):7301-7308, 2011.

[39] Farzin Piltan, Nasri B Sulaiman, Iraj Asadi Talooki and Payman Ferdosali.," Designing On-Line Tunable Gain Fuzzy Sliding Mode Controller Using Sliding Mode Fuzzy Algorithm: Applied to Internal Combustion Engine," world applied science journal (WASJ), 15 (3): 422-428, 2011.

[40] Farzin Piltan, N. Sulaiman, M. H. Marhaban, Adel Nowzary, Mostafa Tohidian," "Design of FPGA based sliding mode controller for robot manipulator," International Journal of Robotic and Automation, 2 (3): 183-204, 2011.

[41] Samira Soltani \& Farzin Piltan, "Design Artificial Nonlinear Controller Based on Computed Torque like Controller with Tunable Gain". World Applied Science Journal,14 (9): 1306-1312, 2011.

[42] Farzin Piltan, H. Rezaie, B. Boroomand, Arman Jahed," Design robust back stepping online tuning feedback linearization control applied to IC engine," International Journal of Advance Science and Technology, 42: 183-204, 2012.

[43] Farzin Piltan, I. Nazari, S. Siamak, P. Ferdosali ,'Methodology of FPGA-based mathematical error-based tuning sliding mode controller" International Journal of Control and Automation, 5(1): 89-110, 2012. 
[44] Farzin Piltan, M. A. Dialame, A. Zare, A. Badri,'Design Novel Lookup table changed Auto Tuning FSMC: Applied to Robot Manipulator" International Journal of Engineering, 6(1): 25-40, 2012.

[45] Farzin Piltan, B. Boroomand, A. Jahed, H. Rezaie ,"Methodology of Mathematical ErrorBased Tuning Sliding Mode Controller" International Journal of Engineering, 6(2): 96-112, 2012.

[46] Farzin Piltan, F. Aghayari, M. R. Rashidian, M. Shamsodini,"A New Estimate Sliding Mode Fuzzy Controller for Robotic Manipulator" International Journal of Robotics and Automation, 3(1): 45-58, 2012.

[47] Farzin Piltan, M. Keshavarz, A. Badri, A. Zargari, "Design novel nonlinear controller applied to robot manipulator: design new feedback linearization fuzzy controller with minimum rule base tuning method" International Journal of Robotics and Automation, 3(1): 1-18, 2012.

[48] Piltan, F., et al. "Design sliding mode controller for robot manipulator with artificial tunable gain". Canaidian Journal of pure and applied science, 5 (2), 1573-1579, 2011.

[49] Farzin Piltan, A. Hosainpour, E. Mazlomian, M.Shamsodini, M.H Yarmahmoudi. "Online Tuning Chattering Free Sliding Mode Fuzzy Control Design: Lyapunov Approach" International Journal of Robotics and Automation, 3(3): 2012.

[50]Farzin Piltan, M.H. Yarmahmoudi, M. Shamsodini, E.Mazlomian, A.Hosainpour. "PUMA-560 Robot Manipulator Position Computed Torque Control Methods Using MATLAB/SIMULINK and Their Integration into Graduate Nonlinear Control and MATLAB Courses" International Journal of Robotics and Automation, 3(3): 2012.

[51] Farzin Piltan, R. Bayat, F. Aghayari, B. Boroomand. "Design Error-Based Linear ModelFree Evaluation Performance Computed Torque Controller" International Journal of Robotics and Automation, 3(3): 2012.

[52] Farzin Piltan, S. Emamzadeh, Z. Hivand, F. Shahriyari \& Mina Mirazaei. " PUMA-560 Robot Manipulator Position Sliding Mode Control Methods Using MATLAB/SIMULINK and Their Integration into Graduate/Undergraduate Nonlinear Control, Robotics and MATLAB Courses" International Journal of Robotics and Automation, 3(3): 2012.

[53] Farzin Piltan, J. Meigolinedjad, S. Mehrara, S. Rahmdel. " Evaluation Performance of $2^{\text {nd }}$ Order Nonlinear System: Baseline Control Tunable Gain Sliding Mode Methodology" International Journal of Robotics and Automation, 3(3): 2012.
[54] Farzin Piltan, M. Mirzaie, F. Shahriyari, Iman Nazari \& S. Emamzadeh." Design Baseline Computed Torque Controller" International Journal of Engineering, 3(3): 2012.

[55] Farzin Piltan, M. A. Bairami, F. Aghayari, S. Allahdadi. " Design Adaptive Artificial Inverse Dynamic Controller: Design Sliding Mode Fuzzy Adaptive New Inverse Dynamic Fuzzy Controller" International Journal of Robotics and Automation, 3(1): 2012.

\section{Authors' Profiles}

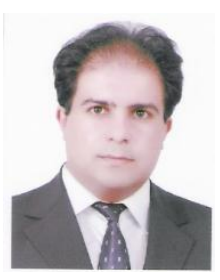

Farzin Piltan was born on 1975, Shiraz, Iran. In 2004 he is jointed the research and development company, SSP Co, Shiraz, Iran. In addition to 7 textbooks, Farzin Piltan is the main author of more than 50 scientific papers in refereed journals. He is editorial board of international journal of control and automation (IJCA), editorial board of IAES international journal of robotics and automation, editorial board of International Journal of Reconfigurable and Embedded Systems and reviewer of (CSC) international journal of robotics and automation. His main areas of research interests are nonlinear control, artificial control system and applied to FPGA, robotics and artificial nonlinear control and IC engine modelling and control.

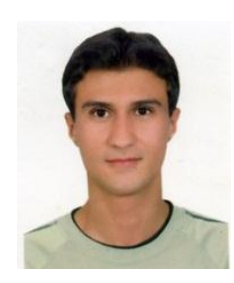

Ali Badri is an electrical engineer researcher of research and development company SSP. Co. He is an expert electrical control engineer in this company. His research activities deal with the robotic control, artificial intelligence and expert system.

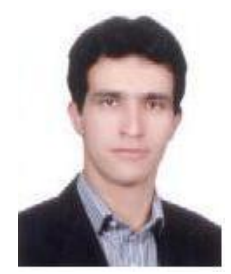

Javad Meigolinedjad is a mechanical engineer researcher of research and development company SSP. Co. He is now pursuing his Master in mechanics. His research activities deal with the robotics and artificial nonlinear control.

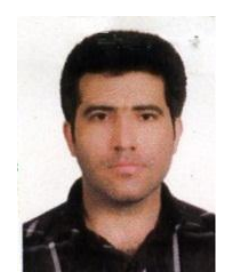

Mohammad Keshavarz is a computer engineer researcher of research and development company SSP. Co. He is now pursuing his Master in computer networking. His research activities deal with the robotics and artificial nonlinear control. 